\title{
A procedure for eliminating sulfide interference on silica colorimetric analysis
}

\author{
Fernando Berro ${ }^{1, *}$, Matteo Lelli ${ }^{2}$, Ilaria Minardi $^{1}$ and Giorgio Virgili ${ }^{1}$ \\ ${ }^{1}$ West Systems s.r.1., Via Don Mazzolari 25, I-56025, Pontedera (PI), Italy \\ ${ }^{2}$ CNR Institute of Geoscience and Earth Resources (CNR-IGG), Via Moruzzi 1, I-56124, Pisa, Italy
}

[Received 10 April 2014; Accepted 29 October 2014; Associate Editor: T. Rinder]

\section{ABSTRACT}

Two different approaches were tested in this study to suppress sulfide interference in the silicomolybdate method of silica determination, namely: oxidation of sulfide to elemental sulfur; and conversion of the sulfide species to $\mathrm{H}_{2} \mathrm{~S}$ and stripping by air bubbling. Based on the results obtained the latter approach is deemed to represent the better and quicker option to eliminate sulfide interference in silica colorimetric analysis.

KEYWORDs: sulfide interference, colorimetric analysis, silica.

\section{Introduction}

Precipitation of amorphous silica represents the main obstacle in the exploitation of geothermal aqueous solutions coming from high-temperature geothermal reservoirs (Gunnarsson and Arnorsson, 2005). The mitigation of silica scaling and the correct disposal of separated geothermal liquids require, among other things, frequent analysis of dissolved silica, which can be performed by means of the molybdate colorimetric method (Jolles and Neurath, 1898; Dienert and Wandenbulcke, 1923). Other analytical methods to quantify the dissolved silica in geothermal aqueous solutions are atomic absorption spectroscopy (AAS) (Chemerys, 1983) and inductively coupled plasma-atomic emission spectroscopy (ICP-AES) (Martin et al., 1994).

The colorimetric method is based on the formation of the silicomolybdate complex which exists in two forms, one of yellow colour, stable under oxidizing conditions, and the other of blue colour, stable under reducing conditions. As the yellow complex is much less absorbant than the blue complex and the silica concentration is large

* E-mail: f.berro@westsystems.com

DOI: $10.1180 /$ minmag.2014.078.6.08 in high-temperature $\left(250-300^{\circ} \mathrm{C}\right)$ geothermal liquids $(460-760 \mathrm{mg} / \mathrm{kg}$ under reservoir conditions assuming saturation with quartz or chalcedony; e.g. Fournier, 1991), the yellow form is preferable for silica analysis of these aqueous solutions.

In the colorimetric method, the rate of reaction of molybdic acid with monosilicic, disilicic and low molecular weight polysilicic acids varies inversely with the degree of polymerization of aqueous silica (Alexander, 1953). Consequently only the so-called 'reactive' silica (including monosilic, disilicic and low molecular weight polysilicic acids) is determined using this analytical method, which is usually adopted as the best technique in geothermal investigations. In fact, AAS and/or ICP-AES are used for determining the total silicon concentration.

Several interferences are known in the colorimetric determination of silica. Interference by salinity is possible (Fanning and Pilson, 1973), but it can be mitigated using calibration standards of salinity similar to the samples. Arsenite,

This paper is published as part of a special issue in Mineralogical Magazine, Vol. 78(6), 2014 entitled 'Mineral-fluid interactions: scaling, surface reactivity and natural systems'. 
arsenate and phosphate form complexes similar to the silicomolybdate one (Atkins and Wilson, 1926; Schwartz, 1934). The very high contents of $\mathrm{P}$ and As are required to produce the same absorption of $\mathrm{Si}$, however. For instance, $1.0 \mathrm{mg}$ of $\mathrm{Si}$ is equivalent to $6.9 \mathrm{mg}$ of $\mathrm{P}$ and $187 \mathrm{mg}$ of $\mathrm{As}$ (Lacroix and Labalade, 1949). This interference is mitigated by the addition of oxalic acid (Mullin and Riley, 1955; APHA, AWWA, WEF, 1999). Ferrous salts also form a coloured complex with molybdates (Schwartz, 1934), but relatively small Fe contents are expected to be present in close-toneutral geothermal reservoir waters. Similar considerations are applicable to $\mathrm{Cu}, \mathrm{Co}$ and $\mathrm{Ni}$ (Mullin and Riley, 1955). High concentrations of fluoride ions (> 50 mg/l; Mullin and Riley, 1955) may lead to generation of hexafluorosilicate anions decreasing the colour intensity of the silicomolybdate complex (Lacroix and Labalade, 1949). However, fluoride concentrations in $\mathrm{NaCl}$ waters typically hosted in geothermal reservoirs are commonly in the range of $1-10 \mathrm{mg} / \mathrm{kg}$ and are usually limited by saturation with respect to fluorite (Ellis and Mahon, 1977).

Reducing ions determine partial conversion of yellow silicomolybdate to the blue form. According to Lacroix and Labalade (1949), interferences caused by reducing substances can be suppressed through the addition of a small amount of ammonium persulfate. Among the reducing substances, hydrogen sulfide, bisulfide and sulfide ions (referred to collectively as 'sulfide species') are probably the most important in geothermal environments. Although sulfide species may disappear without any treatment during long-term sample storage, their interference must be suppressed when silica determination has to be performed immediately after collection. This is the case of the automated system under development by West Systems which is intended for use in monitoring silica concentration in geothermal aqueous solutions.

The classic textbook of Ellis and Mahon (1977) reports that "if sulfide or sulfur dioxide are present, the silicomolybdic acid turns green" without offering any solution to this problem. No mention of $\mathrm{H}_{2} \mathrm{~S}$ interference on colorimetric silica determination is given in the well known report by Giggenbach and Goguel (1989).

Boiling an acidified sample is suggested for sulfide removal by the APHA, AWWA, WEF (1999) Manual. Heat treatment, however, may cause undesirable effects, such as water loss and precipitation of solid phases.
Reaction of ammonium persulfate with sulfide species leads to precipitation of elemental sulfur, as indicated schematically through the following equation:

$\mathrm{H}_{2} \mathrm{~S}+\mathrm{S}_{2} \mathrm{O}_{8}^{2-} \rightarrow \mathrm{S}^{0}+2 \mathrm{SO}_{4}^{2-}+2 \mathrm{H}^{+}$

Elemental sulfur may either cause turbidity or deposit onto the walls of the container in which the reaction occurs. Both effects are detrimental from the analytical point of view and must be avoided. Based on the literature review summarized above, both the oxidation of sulfide to elemental sulfur and the conversion of the sulfide species to $\mathrm{H}_{2} \mathrm{~S}$ and stripping by air bubbling were tested in this investigation, with the aim of selecting the best option for suppressing the interference of sulfide species.

\section{Experimental method}

The methodology adopted consists of the three main steps: (1) preparation of sulfide-bearing synthetic geothermal water samples; (2) removal of $\mathrm{H}_{2} \mathrm{~S}$ from synthetic geothermal waters; and (3) analysis of dissolved reactive silica. These three steps are detailed below. As dissolved sulfide was measured before and after $\mathrm{H}_{2} \mathrm{~S}$ removal, a section on sulfide determination is also given. All solutions were prepared using Milli-Q water with resistivity $>18 \mathrm{M} \Omega \mathrm{cm}$. Whenever possible, plastic materials and laboratory plasticware were employed. All reagents used in this study were of reagent grade.

The $0.1 \mathrm{~N}$ iodine solution was obtained through dilution of a Normex-Carlo Erba (C) glass vial in demineralized water. The sodium thiosulfate $0.02 \mathrm{~N}$ solution was prepared through dilution of a Normex-Carlo Erba C plastic vial in demineralized water.

The 5 wt.\% ammonium molybdate solution was prepared by dissolving $5 \mathrm{~g}$ of ammonium molybdate tetrahydrate in demineralized water, addition of ammonia to $\mathrm{pH} 8-9$ and dilution with water to $100 \mathrm{ml}$. Molybdate dissolution was favoured by heating. The ammonium molybdate solution is expected to be stable for $\sim 1$ month but must be discarded upon the appearance of opalescence or blue colour (APHA, AWWA, WEF, 2005).

\section{Preparation of synthetic geothermal fluid}

A solution containing $2.139 \mathrm{~g} / \mathrm{L} \mathrm{SiO}_{2}$ as sodium metasilicate was used as the dissolved silica stock 
solution. The synthetic geothermal waters were prepared by: (1) dilution of the silica stock solution to obtain a silica concentration of $\sim 800 \mathrm{mg} / \mathrm{kg}$; (2) stripping of oxygen by pure nitrogen bubbling; (3) addition of solid sodium bicarbonate to attain a concentration of $40 \mathrm{mg}$ $\mathrm{HCO}_{3} / \mathrm{kg}$; and (4) bubbling of a $\mathrm{H}_{2} \mathrm{~S}$-containing gas mixture (hydrogen sulfide, 2 wt. $\%$ in nitrogen with $\mathrm{CO}_{2}$ traces) to achieve a sulfide concentration of $30-35 \mathrm{mg} / \mathrm{kg}$.

The measured $\mathrm{pH}$ of synthetic geothermal waters was $\sim 12.2$, an unusually high figure compared to the typical $\mathrm{pH}$ values of natural geothermal waters, which are closely approximated by the relation (Chiodini et al., 1991):

$$
\begin{aligned}
\mathrm{pH}=1.757-0.822 \log \Sigma \text { eq }+ \\
1864 / T-0.0171 \log P_{\mathrm{CO}_{2}}
\end{aligned}
$$

In equation 2, $T$ is temperature $(\mathrm{K}), P_{\mathrm{CO}_{2}}$ is $\mathrm{CO}_{2}$ partial pressure (bar), and $\Sigma$ eq is the total ionic salinity (eq/ $/ \mathrm{kg})$. Nevertheless, at a $\mathrm{pH}$ of 12.2 , the aqueous solution is undersaturated with amorphous silica, a fundamental requirement for this study. In contrast, natural geothermal waters are often oversaturated with amorphous silica at their comparatively low $\mathrm{pH}$ values. The $\mathrm{pH}$ value of 12.2 is in satisfactory agreement with the $\mathrm{pH}$ value of 11.98 given by speciation calculations carried out using the EQ3 software (Wolery and Jarek, 2003), also taking into account that $\mathrm{pH}$ measurement by glass electrode is affected by $\mathrm{Na}$ concentration at $\mathrm{pH}>10$.

Sulfide-free synthetic geothermal waters were also prepared for comparison by performing the steps 1, 2 and 3 only.

\section{Removal of sulfide interference}

As mentioned above, two different approaches were tested to remove sulfide species, namely: (1) oxidation of sulfide to elemental sulfur; and (2) conversion of the sulfide species to $\mathrm{H}_{2} \mathrm{~S}$ and stripping by air bubbling.

The first approach was attempted using either hydrogen peroxide (stabilized $30 \mathrm{wt} \% \%$ hydrogen peroxide solution) or atmospheric air without acidification. The effect of atmospheric air bubbling without prior acidification was estimated by measuring the concentration of sulfide species as a function of time.

In the second approach, the conversion of sulfide species to $\mathrm{H}_{2} \mathrm{~S}$ was achieved through the addition of a small amount of $37 \mathrm{wt} . \% \mathrm{HCl}$ up to a final $\mathrm{pH} \approx 2$, which is consistent with the $\mathrm{pH}$ required for colorimetric silica analysis. Considering the equilibrium constant of aqueous $\mathrm{H}_{2} \mathrm{~S}$ dissociation, which is 6.99 at $25^{\circ} \mathrm{C}$ (Johnson et al., 1992), $99 \%$ of sulfide species is expected to be present as $\mathrm{H}_{2} \mathrm{~S}$ at $\mathrm{pH}$ 4.99. Therefore, $\mathrm{H}_{2} \mathrm{~S}$ is the only sulfide species at $\mathrm{pH} 2$.

\section{Determination of dissolved sulfide}

Hydrochloric acid (37 wt.\%) and stabilized starch indicator solution were used without further treatment. A microdosimeter was used to titrate excess iodine against sodium thiosulfate.

The concentration of total dissolved sulfide was measured as follows: $1 \mathrm{ml}$ of sample was taken using a calibrated micropipette and inserted into a vial with a conical neck. $50 \mu \mathrm{l}$ of $\mathrm{HCl}$ and $100 \mu \mathrm{l}$ of $0.1 \mathrm{~N}$ iodine were added. If the yellow colour of the solution was too pale, it was necessary to add a known extra amount of iodine (e.g. $100 \mu \mathrm{l}$ of $0.1 \mathrm{~N}$ iodine). The aqueous solution was titrated against $0.02 \mathrm{~N}$ thiosulfate until the change in colour from yellow to almost colourless. To better appreciate the endpoint, a drop of starch indicator was added, turning the solution to violet. The titration was continued until the endpoint, when the solution became colourless. The aqueous solution was titrated against $0.02 \mathrm{~N}$ thiosulfate in two steps: first, until the change in colour from yellow to almost colourless and then, to observe the endpoint more clearly, a drop of starch indicator was added, turning the solution to violet. The titration was continued until the endpoint, when the solution became colourless.

\section{Determination of dissolved silica by the molybdate method}

The dissolved silica concentration in synthetic geothermal water was determined on dilutedacidified samples after removal of dissolved sulfide. Two approaches were followed: in one case a 1:20 dilution was performed before acidification and air stripping of $\mathrm{H}_{2} \mathrm{~S}$; in the second case, acidification and air stripping of $\mathrm{H}_{2} \mathrm{~S}$ were done before the 1:20 dilution. In this way, it was possible to evaluate the effects of undesired processes (e.g. silica polymerization, amorphous silica precipitation).

The following procedure was adopted: $5 \mathrm{ml}$ of ammonium molybdate solution were added to $5 \mathrm{ml}$ of sample, already acidified to $\mathrm{pH} 2$ to remove sulfide; the solution was shaken thoroughly and left standing for $12 \mathrm{~min}$; then 
absorbance was measured at $410 \mathrm{~nm}$, using a UVVIS Spectrophotometer Jasco V-530. This procedure is a simplified version of the method 4500$\mathrm{SiO}_{2}$ C. Molybdosilicate Method (APHA, AWWA, WEF, 2005). In particular, oxalic acid was not used because of the absence of $\mathrm{P}$ and As in synthetic geothermal water.

\section{Results}

\section{Oxidation of sulfide to elemental sulfur}

Preliminary tests showed that the addition of hydrogen peroxide leads to turbidity. No further experiments were carried out because turbidity interferes with the colorimetric analysis.

In the two experiments carried out in this study to investigate the $\mathrm{O}_{2}$-driven oxidation of sulfide species, the sulfide concentration decreased from 34 to $4.8 \mathrm{mg} / \mathrm{kg}$ (run 1) and from 36.3 to $4.2 \mathrm{mg} / \mathrm{kg}$ (run 2) in a time interval of $40 \mathrm{~min}$. To test the hypothesis that the reaction of interest is first order, at constant $\mathrm{O}_{2}$ concentration, the natural logarithm of sulfide molality has been plotted as a function of time (h) in Fig. 1. As a linearity was observed, in agreement with the initial hypothesis, experimental data have been fitted against a linear model with a negative slope. Multiplying the slope of this linear regression, $3.115 \mathrm{~h}^{-1}$, by the $\mathrm{O}_{2}$ concentration of air-saturated water, $2.89 \times 10^{-4} \mathrm{~mol} / \mathrm{kg}$, a $\mathrm{k}$ of $10788 \mathrm{~kg}$ of $\mathrm{H}_{2} \mathrm{O} \mathrm{mol}{ }^{-1} \mathrm{~h}^{-1}$ is obtained.

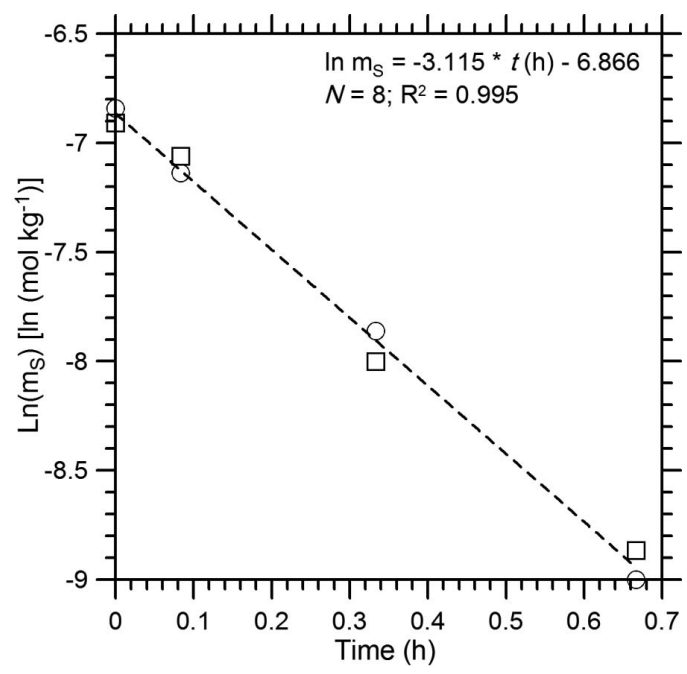

FIG. 1. Natural logarithm of sulfide molality vs. time during $\mathrm{O}_{2}$-driven oxidation of sulfide species in run 1 (circles) and in run 2 (squares).

\section{Conversion of the sulfide species to $\mathrm{H}_{2} \mathrm{~S}$ and stripping by air bubbling}

Adopting this approach, the total sulfide concentration was established as $0.1-1.0 \mathrm{mg} / \mathrm{kg}$ after air bubbling for 1-2 min. The silica concentration of the sulfide-containing aqueous solutions, measured in triplicate on samples diluted at 1:20 either before acidification and air bubbling or after, is comparable with that obtained for the sulfide-free aqueous solutions upon 1:20 dilution, within analytical uncertainties (Table 1). This confirms that the concentration of sulfide species was negligible to nil as no interference was observed.

\section{Discussion}

Oxidation of sulfide species governed by hydrogen peroxide causes significant development of turbidity, possibly due to the precipitation of elemental sulfur, similar to what occurs upon addition of ammonium persulfate, as described by equation 1. Deposition of elemental sulfur onto the walls of the reaction vessel may also take place. Both effects are detrimental from an analytical point of view and therefore unacceptable. This approach was abandoned.

Oxygen-driven oxidation of sulfide species has been investigated previously by, among others, Millero et al. (1987) who concluded that at $\mathrm{pH}$ 8.0 , the overall rate constant $\left(\mathrm{k}, \mathrm{kg}\right.$ of $\mathrm{H}_{2} \mathrm{O} \mathrm{mol}^{-1}$ $\mathrm{h}^{-1}$ ) is given by the following relationships:

$d\left[\mathrm{H}_{2} \mathrm{~S}\right]_{T} / d t=\mathrm{k}\left[\mathrm{O}_{2}\right]\left[\mathrm{H}_{2} \mathrm{~S}\right]_{T}$

$\log \mathrm{k}=11.78-3000 / T+0.44 \mathrm{I}^{1 / 2}$

Based on equations 3 and 4 , at constant $\mathrm{O}_{2}$ concentration, the reaction is first order with $\mathrm{k}$ close to $40 \mathrm{~kg}$ of $\mathrm{H}_{2} \mathrm{O} \mathrm{mol}^{-1} \mathrm{~h}^{-1}$ at the temperature and ionic strength adopted in this study, namely $20^{\circ} \mathrm{C}$ and $0.0206 \mathrm{~mol} / \mathrm{kg}$, respectively. However, the $\mathrm{pH}$ of the aqueous solution tested in this study is close to 12.2 , significantly greater than the $\mathrm{pH}$ value adopted by Millero et al. (1987).

The results of the experiments performed in this study suggest that the reaction is first order at constant $\mathrm{O}_{2}$ concentration, which is consistent with the outcomes of Millero et al. (1987). However, the $\mathrm{k}$ value used in the present study, $10788 \mathrm{~kg}$ of $\mathrm{H}_{2} \mathrm{O} \mathrm{mol}^{-1} \mathrm{~h}^{-1}$, is much greater than that used by Millero et al. (1987), $40 \mathrm{~kg}$ of $\mathrm{H}_{2} \mathrm{O}$ $\mathrm{mol}^{-1} \mathrm{~h}^{-1}$, possibly due to the significantly different $\mathrm{pH}$. 
TABLE 1. Measured silica concentration $\left(\mathrm{mg} \mathrm{SiO}_{2} / \mathrm{l}\right)$ in diluted (1:20) synthetic geothermal waters, either sulfide-free or acidified and bubbled with air to remove sulfide species.

\begin{tabular}{lccc}
\hline Solution/treatment & $1^{\text {st }}$ experiment & $2^{\text {nd }}$ experiment & $3^{\text {rd }}$ experiment \\
\hline Sulfide-free solution & 44.0 & 40.2 & 42.4 \\
Acidification before dilution & 43.4 & 39.1 & 41.3 \\
Acidification after dilution & 41.8 & 40.7 & 41.6 \\
Highest error & $5.0 \%$ & $2.7 \%$ & $2.7 \%$ \\
\hline
\end{tabular}

These results indicate that oxidation of sulfide species driven by atmospheric oxygen in aqueous solutions of $\mathrm{pH}$ close to 12 requires long intervals of time to decrease sulfide concentration below acceptable values. For instance, extrapolation of our experimental data at greater time intervals suggests that total sulfide concentration of 1.0 and $0.1 \mathrm{mg} / \mathrm{kg}$ are achieved after 70 and $110 \mathrm{~min}$, respectively. These time intervals are unacceptable for quick analytical routine. This approach was dismissed.

Sample acidification to $\mathrm{pH} 2$ and stripping using atmospheric air represents a viable option as it is fast and causes virtually complete removal of sulfide species.

Air stripping is a process by which a liquid is brought into intimate contact with a gas so that some undesirable substances present in the liquid phase $\left(\mathrm{H}_{2} \mathrm{~S}\right.$ in the present case) can be released and carried away by the gas (Huang and Shang, 2006). Henry's law constant is a primary indicator of a compound's potential for removal by air stripping. Several models exist for the characterization of gas transfer across the gas/liquid interface. According to the two-film model the overall rate of transfer is controlled by the transfer rate at the liquid-phase boundary for extremely volatile compounds, with large Henry's constant values, such as $\mathrm{H}_{2} \mathrm{~S}$ (Lewis and Whitman, 1924).

That such a simple way to solve this crucial problem for the correct analysis of dissolved silica by means of the colorimetric silicomolybdate method (yellow form) has not been, to the authors' knowledge, described in the geothermal scientific literature, is a surprise.

The only possible but unusual problem with the technique proposed here is the $\mathrm{O}_{2}$-driven oxidation of reduced species (e.g. divalent iron) with consequent precipitation of solid phases (e.g. oxyhydroxides of trivalent iron) and the increase in turbidity. The use of nitrogen or another unreactive gas instead of air would solve this possible problem, as has been suggested to eliminate $\mathrm{H}_{2} \mathrm{~S}$ interference in marine-water samples taken from deep anoxic basins (US EPA, 1997).

Finally, note that the possible presence of polymeric silica species in the stock solution cannot be excluded because of its high silica concentration and high $\mathrm{pH}$ value. It is reasonable to assume that polymeric silica, if any, does not depolymerize upon dilution and acidification, because of the slow rate of depolymerization under acidic conditions (Weres et al., 1980 and references therein). Consequently, the same percentage of polymeric silica species is expected to be present in the stock solution, in the synthetic geothermal waters and in the solutions analysed. Speciation calculations indicate that the only significant polymeric species in the stock solution is the tetramer $\mathrm{H}_{4}\left(\mathrm{H}_{2} \mathrm{SiO}_{4}\right)_{4}^{4-}$, representing $13.45 \%$ of total $\mathrm{Si}$. Therefore, this tetramer could account for $5.4 \mathrm{mg} \mathrm{SiO} / 2 / \mathrm{kg}$ of the $40 \mathrm{mg} \mathrm{SiO} / 2 \mathrm{~kg}$ present in the solutions analysed. It is unclear if this tetramer is molybdate-reactive or not.

\section{Conclusion}

Based on the experiments carried out here, sample acidification to $\mathrm{pH} 2$ and air bubbling represent the most effective and simplest treatment to remove sulfide species, thus suppressing their interference in the colorimetric analysis of dissolved silica using the silicomolybdate method (yellow form). Suppression of sulfide interference is a crucial step in the application of this analytical method as a tool to monitor silica content in liquids from high-temperature reservoirs during the exploitation of geothermal fields.

\section{Acknowledgements}

This research was made possible by a Marie Curie grant from the European Commission in the 
framework of the MINSC ITN (Initial Training Research network), Project number 290040. The authors thank Dr Francesco Norelli for his help with the laboratory work.

\section{References}

Alexander, G.B. (1953) The reaction of low molecular weight silicic acids with molybdic acid. Journal of the American Chemical Society, 75, 5655-5657.

APHA, AWWA, WEF (2005) Standard Methods for the Examination of Water and Wastewater, $21^{\text {st }}$ edition. American Public Health Association, Washington D.C.

Atkins, W.R.G. and Wilson, E.G. (1926) The colorimetric estimation of minute amounts of compounds of silicon, of phosphorus, and of arsenic. Biochemical Journal, 20, 1223-1228.

Chemerys, J.C. (1983) Comparison of analytical methods for the determination of silica in geothermal waters. Journal of Volcanology and Geothermal Research, 16, 57-63.

Chiodini, G., Cioni, R., Guidi, M. and Marini, L. (1991) Chemical geothermometry and geobarometry in hydrothermal aqueous solutions: A theoretical investigation based on a mineral-solution equilibrium model. Geochimica et Cosmochimica Acta, 55, 2709-2727.

Diénert, F. and Wandenbulcke, F. (1923) Sur le dosage de la silice dans les eaux. Comptes Rendus de l'Academie des Sciences, 176, 1478-1480.

Ellis, A.J. and Mahon, W.A.J. (1977) Chemistry and Geothermal Systems. Academic Press, London, $392 \mathrm{pp}$.

Fanning, K. and Pilson, M. (1973) On the spectrophotometric determination of dissolved silica in natural waters. Analytical Chemistry, 45, 136-140.

Fournier, R.O. (1991) Water geothermometers applied to geothermal energy. Pp. 37-69 in: Application of Geochemistry in Geothermal Reservoir Development (F. D'Amore, co-ordinator), UNITAR - United Nations Institute for Training and Resarch, Geneva.

Giggenbach, W.F. and Goguel, R.L. (1989) Collection and analysis of geothermal and volcanic water and gas discharges. Report No. CD 2401. Department of Scientific and Industrial Research, Chemistry Division, Petone, New Zealand.

Gunnarsson, I. and Arnorsson, S. (2005) Impact of silica scaling efficiency of heat extraction from high temperature geothermal fluids. Geothermics, 34, $320-329$.

Huang, J.C. and Shang, C. (2006) Air Stripping. Pp.
47-79 in: Handbook of Environmental Engineering, vol. 4: Advanced Physicochemical Treatment Processes (L.K. Wang, Y.-T. Hung and N.K. Shammas, editors). Springer, Berlin.

Johnson, J.W., Oelkers, E.H. and Helgerson, H.C. (1992) A software package for calculating the standard molal thermodynamic properties of minerals, gases, aqueous species and reactions from 1 to 5000 bars and $0^{\circ}$ to $1000^{\circ} \mathrm{C}$. Computers \& Geosciences, 18, 899-947.

Jolles, A. and Neurath, F.Z. (1898) Eine colorimetrische Method zur Bestimmung der Kieselsaure im Wasser. Angewandte Chemie, 11, 315-316 .

Lacroix, S. and Labalade, M. (1949) Dosage colorimetrique precis de la silice applications. Analytica Chimica Acta, 3, 383-396.

Lewis, G. and Whitman, W. (1924) Principles of gas absorption. Industrial and Engineering Chemistry, 16, 1215-1220.

Martin, T.D., Brockhoff, C.A. and Creed, J.T., EMMC Methods Work Group (1994) Method 200.7 Trace elements in water, solids, and biosolids by inductively coupled plasma-atomic emission spectrometry. Revision 4.4, 60 pp. Environmental Protection Agency (EPA), R-01-010, USA.

Millero, F.J., Hubinger, S., Fernandez, M. and Garnett, S. (1987) Oxidation of $\mathrm{H}_{2} \mathrm{~S}$ in seawater as a function of temperature, $\mathrm{pH}$ and ionic strength. Environmental Science \& Technology, 21, 439-443.

Mullin, J.B. and Riley, J.P. (1955) The colorimetric determination of silicate with special reference to sea and natural waters. Analytica Chimica Acta, 12, $162-176$.

Schwartz, M.C. (1934) Colorimetric determination of silica in boiler water. Industrial \& Engineering Chemistry Analytical Edition, 6 (5), 364-367.

US EPA (1997) Determination of dissolved silicate in estuarine and coastal waters by gas segmented continuous flow colorimetric analysis (US EPA 366.0). National Exposure Research Laboratory, Office of Research and Development. U.S. Environmental Protection Agency, Cincinnati, Ohio, USA.

Weres, O., Yee, A. and Tsao, L. (1980) Kinetics of silica polymerization. Lawrence Berkeley Laboratory U.S. Department of Energy Report LBL-7033, $256 \mathrm{pp}$.

Wolery, T.W. and Jarek, R.L. (2003) Software user's manual. EQ3/6, Version 8.0. U.S. Department of Energy Report, Sandia National Laboratories, New Mexico, USA, 376 pp. 